\title{
Análise da Qualidade das Águas Superficiais da Bacia Hidrográfica do Córrego Moeda, Três Lagoas/MS, no Verão de 2014
}

Quality Analysis Surface Water of Hydrographic Basin Stream Moeda, Três Lagoas/MS in Summer 2014

Análisis de la Calidad de Aguas de Cuenca Hidrográfica del Arroyo Moeda, Três Lagoas/MS en el Verano de 2014

Weslen Manari Gomes Mestrando em Geografia pela Universidade Federal de Mato Grosso do Sul, UFMS, Brasil. weslenmanari@hotmali.com

Rafael Brugnolli Medeiros Doutorando em Geografia pela Universidade Federal da Grande Dourados, UFGD, Brasil. rafael_bmedeiros@hotmail.com

\section{Angélica Estigarribia São Miguel}

Graduada e Mestre em Geografia pela Universidade Federal de Mato Grosso do Sul, UFMS, Brasil. angelica.esm@hotmail.com 


\section{RESUMO}

A análise da qualidade das águas superficiais é utilizada como uma das principais análises, que determinam possíveis modificações no equilíbrio de uma bacia hidrográfica, dessa forma, é extremamente necessária sua identificação, bem como, os pontos em que estão ocorrendo anomalias que acabam resultando em um enquadramento em classes mais altas segundo as resoluções do CONAMA. Com isso, esta pesquisa tem como objetivo, analisar a qualidade das águas superficiais da bacia hidrográfica do córrego Moeda, mediante a aferição do oxigênio dissolvido, pH, turbidez, temperatura do ar e água e condutividade elétrica. Para isso, serão utilizadas as resoluções do CONAMA 357/2005 e 430/2011, fornecendo importantes informações a cerca dos recursos hídricos desta bacia hidrográfica. 0 equipamento utilizado para a análise destes parâmetros é o Horiba U-50 Series Multiparameter water Quality Unit's. Os resultados apontaram para um enquadramento na classe IV nos pontos 8 e 11 , devido principalmente à falta de mata ciliar e ao represamento das águas, respectivamente, que acabam ocasionando na redução do OD. Outro local que merece destaque é ponto 1, que ficou enquadrado na classe III, devido à sua alta condutividade elétrica e baixo OD, principalmente por seu um local onde o gado adentra até suas águas, modificando o equilíbrio deste ambiente aquático. No geral a BHCM ficou enquadrada na classe II, preconizando sua utilização para o abastecimento humano desde que haja um tratamento convencional.

PALAVRAS-CHAVE: Bacia Hidrográfica. Qualidade das Águas Superficiais. Enquadramento.

\section{SUMMARY}

The analysis of the quality of surface water is used as one of the main analyzes, which determine possible changes in the balance of a hydrographic basin, therefore, it is extremely necessary identification as well as the points that are occurring anomalies that end up resulting in a framework in higher classes according to resolutions of CONAMA. Thus, this research aims to analyze the quality of surface waters of the hydrographic basin of the stream Moeda, through the measurement of dissolved oxygen, $\mathrm{pH}$, turbidity, air temperature and water and electrical conductivity. For this, the resolutions will be used CONAMA 357/2005 and 430/2011, providing important information about water resources of this watershed. The equipment used for the analysis of these parameters is the Horiba U-50 Series Multiparameter water Quality Unit's. The results pointed to a framework in class IV in paragraphs 8 and 11 , mainly due to the lack of riparian vegetation and impoundment of water, respectively, which end up causing reduction in the OD. Another place worth mentioning is point 1, which was framed in the class III, due to its high electrical conductivity and low OD, mainly because its a place where cattle enters to their waters, changing the balance of the aquatic environment. Overall the BHCM was framed in class II, recommending its use for human consumption provided that there is a conventional treatment.

KEYWORDS: Hydrographic Basin. Quality of Surface Water. Framework.

\section{RESUMEN}

El análisis de la calidad de las aguas superficiales se utiliza como uno de los principales análisis, que determinan los posibles cambios en el equilibrio de una cuenca hidrográfica, por lo tanto, es la identificación extremadamente necesaria, así como los puntos que se están produciendo anomalías que terminan resultando en una marco en las clases más altas de acuerdo con las resoluciones de CONAMA. Por lo tanto, la presente investigación tiene como objetivo analizar la calidad de las aguas superficiales de la cuenca hidrográfica del arroyo Moeda, a través de la medición de oxígeno disuelto, $\mathrm{pH}$, turbidez, temperatura del aire y del agua y la conductividad eléctrica. Para ello, las resoluciones serán utilizados CONAMA 357/2005 y 430/2011, que proporciona información importante sobre los recursos hídricos de esta cuenca. El equipo utilizado para el análisis de estos parámetros es la Unidad de Calidad del agua Horiba T-50 Series de multiparámetro. Los resultados apuntan a un marco en la clase IV en los párrafos 8 y 11 , principalmente debido a la falta de vegetación de ribera y el embalse del agua, respectivamente, que terminan provocando la reducción en el diámetro exterior. Otro lugar digno de mención es el punto 1, que se enmarca en la clase III, debido a su alta conductividad eléctrica y baja OD, sobre todo porque es un lugar donde el ganado entra a sus aguas, cambiando el equilibrio del medio ambiente acuático. En general, el BHCM se enmarcó en la clase II, recomendando su uso para el consumo humano, siempre que hay un tratamiento convencional.

PALABRAS CLAVE: Cuenca Hidrográfica. Calidad de las Aguas Superficiales. Marco. 


\section{INTRODUÇÃO}

A qualidade das águas superficiais pode ser compreendida como uma representação de diversos processos que ocorrem nos ambientes aquáticos, traduzindo diretamente no funcionamento destes ecossistemas, sobretudo, em locais onde ocorrem modificações de seus parâmetros, seja de forma natural e/ou antrópica.

Neste sentido, a Lei $n^{\circ} 9.433 / 97$, proporcionou uma importante melhoria com relação à sua gestão integrada, bem como, a utilização da bacia hidrográfica como unidade de estudo e planejamento, visando que o uso antrópico interfira de maneira menos significativamente sobre o ambiente, ou seja, que ocorra um equilíbrio.

Rebouças (2002) afirma que a água é um elemento finito, dessa forma, necessita de uma preocupação com sua utilização, sendo também um elemento químico natural, que possui um bem econômico passível de utilização para esse fim.

Portanto, as características das águas superficiais estão ligadas diretamente com outros elementos que compõe o sistema bacia hidrográfica, e é dependente destes (clima, solos, rocha, vegetação, atividades industriais, agrícolas, urbanas), causando assim, modificações em sua composição física, química e biológica.

Diante desta grande problemática, o monitoramento destas águas superficiais se mostra necessário, tanto é que Toledo e Nicolella (2002) afirmam que:

[...] o uso de índices de qualidade de água é uma tentativa que todo programa de monitoramento de águas superficiais prevê como forma de acompanhar, através de informações resumidas, a possível deterioração dos recursos hídricos ao longo da bacia hidrográfica ou ao longo do tempo (TOLEDO e NICOLELLA, 2002. p. 182).

Os benefícios de equipamentos mais atualizados e modernos possibilitam a mensuração em campo e estão sendo amplamente utilizados para monitoramentos de qualidade de água, utilizando-se do oxigênio dissolvido - OD, como parâmetro principal e complementares como potencial hidrogeniônico - $\mathrm{pH}$, condutividade elétrica - $\mathrm{CE}$, temperatura do ar e da água e turbidez.

Segundo Tchobanoglous e Schroeder (1985) o OD é amplamente utilizado como principal parâmetro da qualidade de água e serve para determinar o impacto de poluentes sobre corpos d'água, pois é um dos mais importantes fatores no desenvolvimento de qualquer planejamento na gestão de recursos hídricos.

Diante do levantamento de informações, torna-se possível analisar a qualidade de suas águas, já buscando seu enquadramento nas resoluções 357/2005 e 430/2011 do CONAMA, que determinam as principais utilizações destas águas diante dos índices obtidos nos parâmetros analisados na Bacia Hidrográfica do Córrego Moeda - BHCM.

A BHCM tem área de $247,67 \mathrm{~km}^{2}$ e fica localizada ao sul da sede do município de Três Lagoas/MS, na margem direita do rio Paranáentre as coordenadas geográficas de $20^{\circ} 50^{\prime} 00^{\prime \prime} \mathrm{e}$ $21^{\circ} 01^{\prime} 10^{\prime \prime}$ de latitude $S$ e $51^{\circ} 44^{\prime} 55^{\prime \prime}$ e $52^{\circ} 01^{\prime} 08^{\prime \prime}$ de longitude W, (Figura 1) 
Figura 1: Localização da BHCM, Três Lagoas/MS.

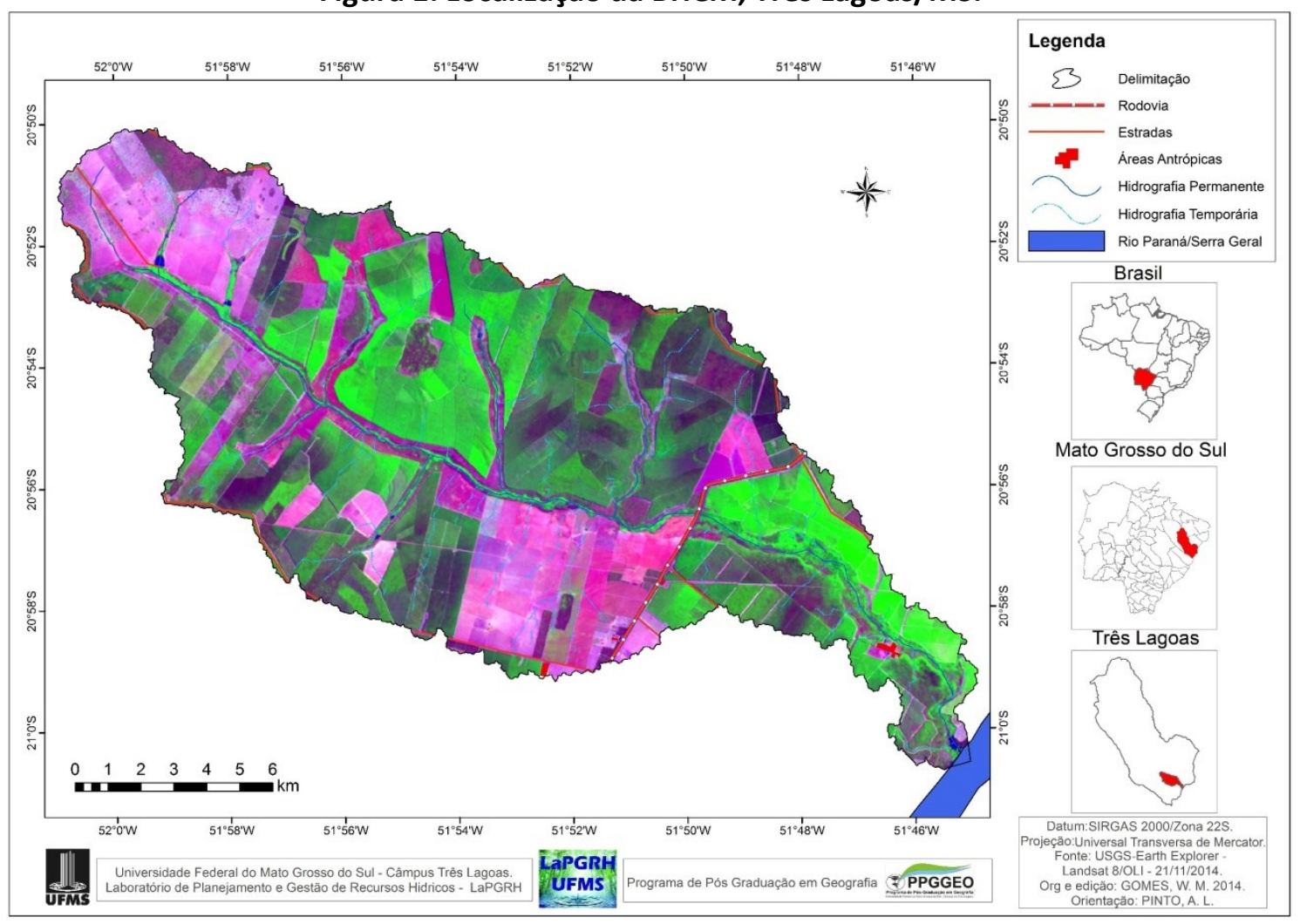

\section{OBJETIVOS}

O objetivo desta pesquisa é analisar a qualidade das águas superficiais da bacia hidrográfica do córrego Moeda, mediante a aferição do oxigênio dissolvido, $\mathrm{pH}$, turbidez, temperatura do ar e água e condutividade elétrica. Para isso, serão utilizadas as resoluções do CONAMA 357/2005 e 430/2011, fornecendo importantes informações a cerca dos recursos hídricos desta bacia hidrográfica.

\section{METODOLOGIA}

A qualidade das águas superficiais é definida devido às suas características físicas e químicas, as quais são determinadas por meio de análises realizadas em trabalhos de campo. Na análise dos parâmetros para mensuração da qualidade das águas superficiais da BHCM foi utilizado o Horiba U-50 Series Multiparameter water Quality Unit's para a medição e geração dos parâmetros aferidos no campo. Cada variável tem sua importância na análise da qualidade das águas. Os parâmetros são o Oxigênio Dissolvido (OD), pH, Temperatura do ar e da água, Condutividade elétrica, Turbidez.

Para a análise dos parâmetros para a verificação da qualidade das águas superficiais do Córrego Moeda, foram empregados os equipamentos e métodos, relacionados no Quadro 1. 
Quadro 6: Parâmetros, equipamento e métodos utilizados para análise da qualidade das águas superficiais da BHCM, Três Lagoas/MS.

\begin{tabular}{|c|c|}
\hline $\begin{array}{l}\text { Parâmetros/ } \\
\text { Método }\end{array}$ & Definição \\
\hline $\begin{array}{l}\text { Oxigênio Dissolvido - OD/ } \\
\text { Espectrofotométrico }\end{array}$ & $\begin{array}{l}\text { O Oxigênio Dissolvido - OD é um gás solúvel em água, com concentrações } \\
\text { variadas. Segundo Araújo et. al. (2004) o oxigênio dissolvido pode ser utilizado } \\
\text { como indicador de qualidade das águas superficiais, pois a proliferação } \\
\text { bacteriológica depende diretamente de suas concentrações, constituindo de } \\
\text { metodologia de rápida análise, passível de realização no campo. }\end{array}$ \\
\hline $\begin{array}{l}\text { Condutividade Elétrica - } \\
\text { CE/Eletrométrico }\end{array}$ & $\begin{array}{l}\text { A Condutividade Elétrica - CE é a capacidade que a água possui de conduzir } \\
\text { corrente elétrica. Este parâmetro está relacionado com a presença de íons } \\
\text { dissolvidos na água, que são partículas carregadas eletricamente. Quanto maior } \\
\text { for à quantidade de íons dissolvidos, maior será a condutividade elétrica da água. } \\
\text { Em águas continentais, os íons diretamente responsáveis pelos valores da } \\
\text { condutividade são, entre outros, o cálcio, o magnésio, o potássio, o sódio, } \\
\text { carbonatos, carbonetos, sulfatos e cloretos (SILVA e HERMES, 2004). }\end{array}$ \\
\hline Turbidez/Eletrométrico & $\begin{array}{l}\text { A turbidez para Pinto (1998) é a alteração da penetração da luz provocada por } \\
\text { partículas em suspensão, como bactérias, argilas e silte ou fontes de poluição que } \\
\text { lançam materiais finos e outras substâncias na água. Certamente, a presença } \\
\text { dessas substâncias provoca a dispersão e a absorção da luz, dando à água } \\
\text { aparência nebulosa, esteticamente indesejável e potencialmente perigosa. Enfim, } \\
\text { um alto valor de turbidez prejudica criando uma barreira sobre a água, reduzindo } \\
\text { a fotossíntese da vegetação enraizada submersa e das algas. Esse } \\
\text { desenvolvimento reduzido pode suprimir a produtividade de peixes, além disso, } \\
\text { afeta adversamente os usos doméstico, industrial e recreacional da água. }\end{array}$ \\
\hline $\mathrm{pH} /$ Eletrométrico & $\begin{array}{l}\text { O Potencial Hidrogeniônico - } \mathrm{pH} \text { é quimicamente a medida de concentração de } \\
\text { íons } \mathrm{H}+\mathrm{e} \text { íons } \mathrm{OH} \text { presentes na solução, é uma das determinações de qualidade } \\
\text { de água mais frequentemente executadas, apresentando a acidez ou a } \\
\text { alcalinidade das águas, que podem ter origens em fatores naturais do terreno ou } \\
\text { resultantes de poluentes dissolvidos na água. A escala de } \mathrm{pH} \text { é constituída de } \\
\text { uma série de números variando de } 0 \text { a } 14 \text {, os quais denotam vários graus de } \\
\text { acidez ou alcalinidade. Valores abaixo de } 7 \text { e próximos de zero indicam aumento } \\
\text { de acidez, neutra valor igual a } 7 \text {, enquanto valores de } 7 \text { a } 14 \text { indicam aumento da } \\
\text { basicidade. Os peixes vivem em uma determinada faixa de valor de pH, que na } \\
\text { maioria das vezes os valores oscilam entre } 5,5 \text { e } 7,5 \text {, geralmente os peixes } \\
\text { adoecem rapidamente quando o valor de pH é inferior a } 4,5 \text { ou maior que } 9,0 \text {. A } \\
\text { vida aquática depende do pH, sendo recomendável a faixa de } 6 \text { a 9. (CETESB, } \\
\text { 1987). }\end{array}$ \\
\hline $\begin{array}{l}\text { Temperatura } \\
\text { Ar e Água/Eletrométrico }\end{array}$ & $\begin{array}{l}\text { Silveira (2004) a temperatura da água é um fator importante na regulação das } \\
\text { características físicas e bióticas dos riachos. E, certamente lagos, lagoas e lagunas } \\
\text { se assemelham a essa definição. A Temperatura }(\text { oC) acelera as reações químicas, } \\
\text { reduz a solubilidade dos gases, acentua a sensação de sabor e odor. A } \\
\text { temperatura da água é tratada como um fator importante na regulação das } \\
\text { características físicas e bióticas dos riachos. Com o corte da vegetação ripária há } \\
\text { um aumento da temperatura da água, diminuindo a capacidade de solubilização } \\
\text { do oxigênio. }\end{array}$ \\
\hline
\end{tabular}

A Tabela 1 e Quadro 2 apresentam os limites para o enquadramento das águas e principais usos das águas doces brasileiras, respectivamente, utilizando-se da legislação do Conselho Nacional do Meio Ambiente (CONAMA). A utilização destas resoluções é devida à entrada de efluentes, principalmente industrial e até pelo próprio uso, cobertura e manejo da terra nesta área (adubos químicos), sendo possível utilizar os parâmetros para o enquadramento de qualidade para águas superficiais. Estes parâmetros identificam a contaminação dos mananciais hídricos, sendo que, o resultado encontrado, será determinante para os objetivos desta pesquisa, pois acaba enquadrando as águas superficiais para consumo humano e 
apontará as possíveis causas que acabam alterando o equilíbrio deste ambiente, buscando sempre apontar sugestões que auxiliem em um ordenamento mais sustentável desta área.

$\mathrm{Na}$ identificação das classes de limitações de uso da água, foram utilizadas cores de acordo com CONAMA, adaptando do índice de qualidade das águas - IQA, seguidos pela CETESB (2006). Este índice citado é uma pesquisa de opinião de acordo com especialistas em qualidade de água, que apontaram qual parâmetro e o peso que cada um deles exerce sobre a qualidade das águas. Entretanto, de todos os parâmetros utilizados no IQA, devido a facilidade na mensuração do Horiba U-50 Series Multiparameter water Quality Unit's, foram utilizados apenas nove parâmetros, Quadro 2.

Tabela 1: Limites dos parâmetros analisados para enquadramento nas classes das águas doces no Brasil.

\begin{tabular}{c|l}
\hline Classes & \multicolumn{1}{c}{ Limites para o Enquadramento } \\
\hline \multirow{5}{*}{ Especial } & Nas águas de classe especial deverão ser mantidas as condições naturais do corpo de água. \\
& OD: $+10,0 \mathrm{mg} / \mathrm{L} ;$ \\
& Ph: 6,0 a 9,$0 ;$ \\
& Turbidez: 0 a $20 \mathrm{NTU;}$ \\
& Condutividade Elétrica: 0 a $50 \mathrm{uS} / \mathrm{cm} ;$ \\
\hline \multirow{5}{*}{ I } & OD: 10 a $6 \mathrm{mg} / \mathrm{L} ;$ \\
& pH: 6,0 a 9,$0 ;$ \\
& Turbidez: 20 a 40 NTU; \\
& Condutividade Elétrica: 50 a $75 \mathrm{uS} / \mathrm{cm} ;$ \\
\hline \multirow{5}{*}{ II } & OD: 6 a $5 \mathrm{mg} / \mathrm{L} ;$ \\
& pH: 6,0 a 9,$0 ;$ \\
& Turbidez: 40 a 70 NTU; \\
& Condutividade Elétrica: 75 até $100 \mathrm{uS} / \mathrm{cm} ;$ \\
\hline \multirow{3}{*}{ III } & OD: 5 a $4 \mathrm{mg} / \mathrm{L} ;$ \\
& pH: 6,0 a 9,$0 ;$ \\
& Turbidez: 70 a $100 \mathrm{NTU} ;$ \\
& Condutividade Elétrica: 100 a $150 \mathrm{uS} / \mathrm{cm} ;$ \\
\hline \multirow{3}{*}{ IV } & OD: $-4 \mathrm{mg} / \mathrm{L} ;$ \\
& pH: 6,0 a 9,$0 ;$ \\
& Turbidez: +100 NTU; \\
& Condutividade Elétrica: $+150 \mathrm{uS} / \mathrm{cm} ;$ \\
\hline
\end{tabular}

Fonte: Adaptação das resoluções CONAMA 357/2005 e 430/2011, por Pinto et. al. (2010) 
Quadro 2: Classificação das águas doces brasileiras, segundo seus usos preponderantes, de acordo com a Resolução CONAMA n. 430/2011.

\begin{tabular}{|c|l|}
\hline Classes & \multicolumn{1}{|c|}{ Principais Usos } \\
\hline Especial & $\begin{array}{l}\text { Consumo humano com desinfeç̧ão; Preservação de equilíbrio natural das comunidades } \\
\text { aquáticas; Preservação dos ambientes aquáticos em unidades de conservação de proteção } \\
\text { integral. }\end{array}$ \\
\hline \multirow{2}{*}{ I } & $\begin{array}{l}\text { Consumo humano, após tratamento simplificado; Proteção das comunidades aquáticas; } \\
\text { Recreação de contato primário (natação, esqui aquático e mergulho) Resolução conAMA n. } \\
274, \text { de 2000; Irrigação de hortaliças que são consumidas cruas e de frutas que se desenvolvam } \\
\text { rentes ao solo e que sejam ingeridas sem remoção de películas e à proteção das comunidades } \\
\text { aquáticas em Terras Indígenas. }\end{array}$ \\
\hline II & $\begin{array}{l}\text { Abastecimento para consumo humano, após tratamento convencional, à proteção das } \\
\text { comunidades aquáticas, à recreação de contato primário, tais como natação, esqui aquático e } \\
\text { mergulho, Resolução conAMA n. 274, de 2000, à irrigação de hortaliças, plantas frutíferas e de } \\
\text { parques, jardins, campos de esporte e lazer, com os quais o público possa vir a ter contato } \\
\text { direto e à aqüicultura e à atividade de pesca. }\end{array}$ \\
\hline III & $\begin{array}{l}\text { Abastecimento para consumo humano, após tratamento convencional ou avançado, à irrigação } \\
\text { de culturas arbóreas, cerealíferas e forrageiras, à pesca amadora, à recreação de contato } \\
\text { secundário e à dessedentação de animais. }\end{array}$ \\
\hline IV & Navegação e à harmonia paisagística \\
\hline
\end{tabular}

Fonte: Resoluções CONAMA 430/2011.

\section{RESULTADOS}

No monitoramento da qualidade das águas na estação do verão, Tabela 2 e Figura 2, foi possível o enquadramento de grande parte dos pontos de coleta $(2,3,5,6,7,9$ e 10) na Classe I, que preconiza seu uso para consumo humano desde que seja realizado um tratamento simplificado, podendo ser utilizadas para recreação de contato primário e proteção das comunidades aquáticas.

Tabela 2: Parâmetros de qualidade das águas superficiais da BHCM, no verão de 2014.

\begin{tabular}{|c|c|c|c|c|c|c|c|}
\hline Pontos & $\begin{array}{c}\text { CE. } \\
(\mu \mathrm{S} / \mathrm{cm})\end{array}$ & $\begin{array}{l}\text { OD. } \\
\text { (mg/L) }\end{array}$ & $\begin{array}{c}\text { Temp. } \\
\mathrm{Ar} \\
\left({ }^{\circ} \mathrm{C}\right)\end{array}$ & $\begin{array}{c}\text { Temp. } \\
\text { H2O } \\
\left({ }^{\circ} \mathrm{C}\right)\end{array}$ & pH & $\begin{array}{l}\text { Turbidez } \\
\text { (NTU) }\end{array}$ & $\begin{array}{c}\text { Classes de } \\
\text { Enquadramento }\end{array}$ \\
\hline 1 & 53,00 & 4,00 & 28,9 & 29,0 & 7,00 & 28,00 & III \\
\hline 2 & 19,00 & 8,10 & 26,7 & 24,7 & 6,70 & 9,85 & I \\
\hline 3 & 22,00 & 8,20 & 27,1 & 26,1 & 6,80 & 5,30 & I \\
\hline 4 & 22,00 & 5,70 & 29,9 & 27,8 & 7,40 & 7,16 & II \\
\hline 5 & 17,00 & 7,60 & 30,8 & 23,4 & 7,10 & 10,10 & I \\
\hline 6 & 17,00 & 7,70 & 35,6 & 28,7 & 7,50 & 8,74 & I \\
\hline 7 & 17,00 & 7,90 & 35,7 & 25,1 & 7,40 & 8,00 & I \\
\hline 8 & 25,00 & 1,70 & 30,8 & 25,6 & 7,10 & 35,20 & IV \\
\hline 9 & 16,00 & 8,40 & 32,7 & 25,1 & 7,60 & 8,72 & I \\
\hline 10 & 16,00 & 8,90 & 32,5 & 24,1 & 7,20 & 9,59 & I \\
\hline 11 & 36,00 & 2,80 & 30,2 & 31,4 & 7,70 & 8,00 & IV \\
\hline Média & 23,64 & 6,45 & 30,99 & 26,45 & 7,23 & 12,61 & II \\
\hline
\end{tabular}


Figura 2: Variação dos parâmetros obtidos por meio do monitoramento da qualidade das águas da BHCM, no

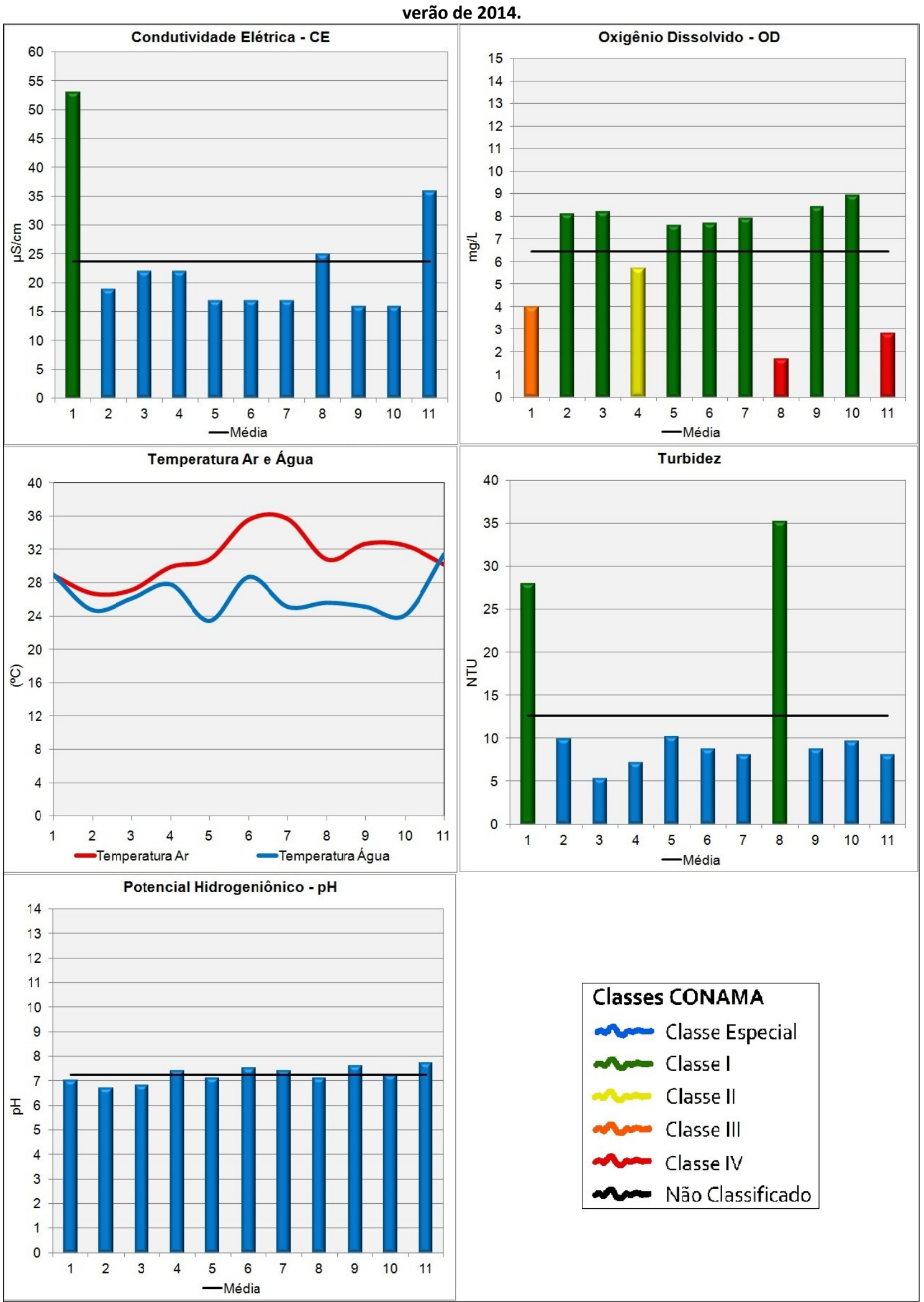


Os dados do verão, apontam baixos níveis de oxigênio dissolvido, no Ponto 1, localizado no alto curso da BHCM, quando foi mensurado apenas $4,00 \mathrm{mg} / \mathrm{L}$, esta baixa concentração pode ser explicado devido a grande quantidade de matéria orgânica e fezes bovinas existentes no local, que acabam consumindo o OD e gerando reações químicas que elevam a turbidez e condutividade elétrica. É também necessário destacar que há grande quantidade de gado que adentra este local servindo de bebedouro, gerando pisoteio, contribuindo para a elevação da turbidez.

Dos parâmetros analisados, o OD é o principal indicador de qualidade de água superficial, assim, este ponto se enquadrou na classe III, que segundo o CONAMA, resolução 430 de 2011, preconiza o uso para "Abastecimento para consumo humano, após tratamento convencional ou avançado, à irrigação de culturas arbóreas, cerealíferas e forrageiras, à pesca amadora, à recreação de contato secundário e à dessedentação de animais".

O ponto 4 foi enquadrado como Classe II, principalmente devido ao OD que chegou à $5,70 \mathrm{mg} / \mathrm{L}$, número considerado baixo para os padrões de balneabilidade, já que todos os demais parâmetros deste ponto, apontaram para Classe Especial.

O córrego Buriti, Ponto 8, é um dos maiores problemas enfrentados pela BHCM, pois é extremamente importante por se tratar de um dos maiores afluentes do córrego Moeda, onde suas águas foram encontradas com péssima qualidade, na Classe IV, preconizando apenas sua utilização para harmonia paisagística, de acordo com resoluções do CONAMA 357/2005 e 430/2011.

Assim como o ponto 1 , o ponto 11 também foi influenciado pela concentração da matéria orgânica existente na área, pois o "brejo" que existe em sua margem esquerda acaba elevando sua turbidez e reduzindo seu $O D$, neste caso, apenas O OD sofreu interferência, chegando à $2,80 \mathrm{mg} / \mathrm{L}$, sendo determinante para o enquadramento na Classe IV.

No ponto 10 , foi obtido o maior $\mathrm{OD}, 8,90 \mathrm{mg} / \mathrm{L}$, este valor foi determinado, principalmente pelo turbilhonamento, gerado pela alta velocidade de fluxo e por seu leito, ser formado por cascalhos, elevando a oxigenação da água, Figura 3. 
Figura 3: Baixo curso da BHCM, ponto 10, alta velocidade e rugosidade de fundo, repleto de cascalho, aumentam o turbilhonamento da água, elevando seu OD no verão de 2014.

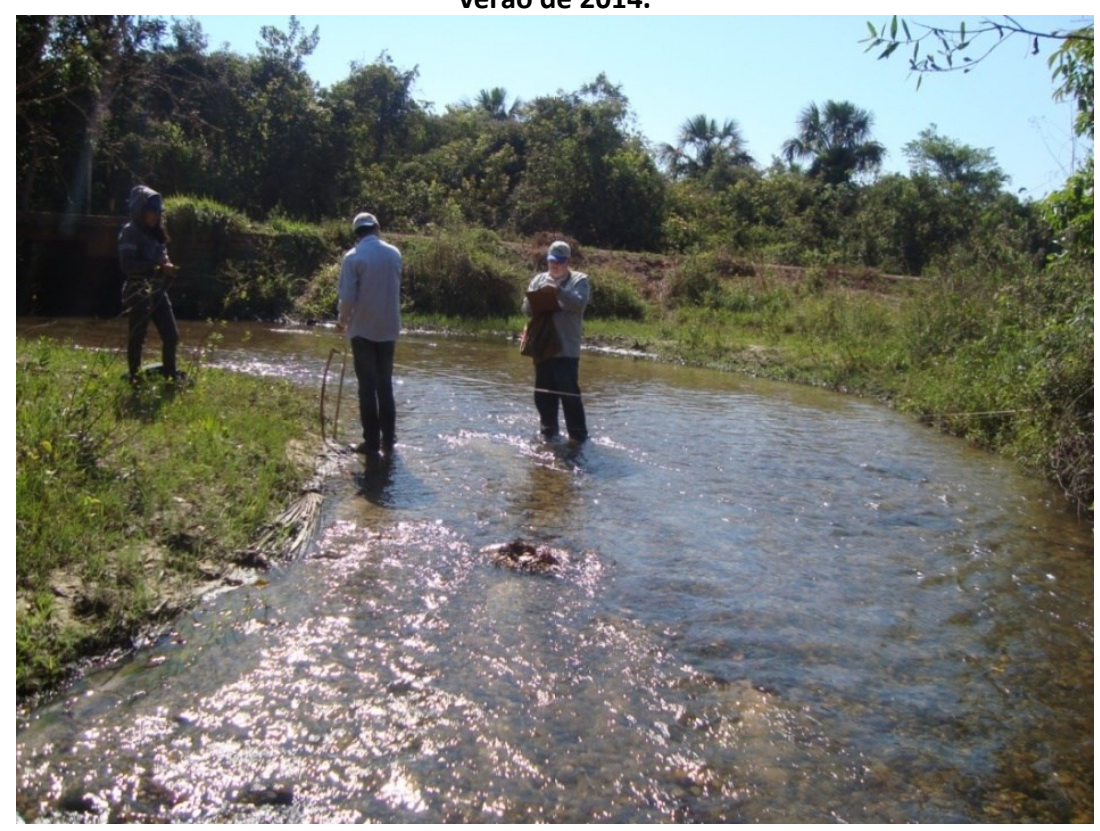

Como o pH está ligado diretamente com as temperaturas das águas, o ponto 2 ficou caracterizado por apresentar 24,700 de temperatura e 6,70 de potencial hidrogeniônico, ou seja, já apresenta índice de água pouco ácida, entretanto, ainda dentro do limite de 6,0 a 9,0, expresso pelas resoluções CONAMA 357/2005 e 430/2011.

De todos os valores apresentados no verão de 2014, destaca-se a influência do OD no enquadramento dos pontos de coleta das águas, sendo necessário destacar também, a influência que as precipitações têm sobre a qualidade das águas, dependendo da utilização das terras próximas aos pontos de coleta, a intensidade das chuvas poderá ocasionar na renovação das águas dos canais fluviais, elevando o oxigênio dissolvido e mantendo o pH estabilizado. Com isso, no verão é notável a predominância da Classe I.

\section{CONCLUSÃO}

As intervenções que o homem faz na natureza causa um desequilíbrio na mesma. Essas intervenções devem ser feitas com o planejamento adequado para que os impactos positivos dessas intervenções sejam maximizados e os negativos minimizados. Para isso a bacia hidrográfica é tomada como unidade de estudo, planejamento e gestão, pois tem caráter integrador e possibilita avaliar a dinâmica da natureza e as interações entre os diversos elementos que compõem a paisagem e o principal elemento que demonstra qualquer tipo de alteração no ambiente, são os recursos hídricos, por este motivo é tomado como objeto de estudo desta pesquisa. 
Por meio das análises realizadas, mostra-se que córrego Buriti (ponto 8) é um grande exemplo da importância das matas ciliares para a qualidade das águas superficiais, pois sua falta de proteção, levou ao OD reduzido e os buritis existentes a morrerem.

Todas estas problemáticas influenciam expressivamente na qualidade das águas superficiais, sobretudo na perda de solo, adubação, pesticidas, que acabam sendo escoados até os recursos hídricos, alterando os parâmetros físicos e químicos das águas. Com isso, houve algumas variações em sua composição ao longo dos pontos monitorados no verão de 2014 , apontando para a pior classificação nos pontos 8 e 11, que devido à falta de vegetação e ao represamento da água, respectivamente, acabaram modificando a qualidade das águas superficiais.

De modo geral, a BHCM apontou para a classe II, que preconiza seu uso, segundo as resoluções 357/2005 e 430/2011 do CONAMA, para o abastecimento humano desde que haja um tratamento convencional, servindo de proteção às comunidades aquáticas, à recreação de contato primário, à irrigação de hortaliças, plantas frutíferas e de parques, jardins, campos de esporte e lazer, à aqüicultura e à atividade de pesca.

\section{REFERÊNCIAS BIBLIOGRÁFICAS}

ARAÚJO, S. C. de S.; SALLES, P. S. B. de A.; SAITO, C. H. Modelos qualitativos, baseados na dinâmica do oxigênio dissolvido, para avaliação da qualidade das águas em bacias hidrográficas. Desenvolvimento tecnológico e metodológico para medição entre usuários e comitês de bacia hidrográfica. Brasília: Departamento de Ecologia. Editora da UNB, 2004. p.9-24.

BRASIL Conselho Nacional do Meio Ambiente - CONAMA Resolução 357/2005, Enquadramento dos Corpos Hídricos Superficiais no Brasil.. Governo Federal, Brasília. Publicada no DOU n 92, de 13 de maio de 2011, Seção 1, 89p.

BRASIL Conselho Nacional do Meio Ambiente - CONAMA Resolução 403/2011, Enquadramento dos Emissários de Esgoto que são Lançados em Corpos Hídricos Superficiais no Brasil.. Governo Federal, Brasília. Publicada no DOU n 92, de 13 de maio de 2011, Seção 1, 89p.

CETESB - Companhia Ambiental do Estado de São Paulo. Guia de coleta e preservação de amostras de água. São Paulo, 1987: 150 p. (Séries guias)

PINTO, A. L. Saneamento Básico e suas Implicações na Qualidade das Águas Subterrâneas da Cidade de Anastácio (MS). 1998. 175 p. Tese (Doutorado e Geociências) - Universidade Estadual Paulista/Instituto de Geociências e Ciências Exatas, Rio Claro, 1998.

REBOUÇAS, A. da C. Água doce no mundo e no Brasil. In: REBOUÇAS, A. da C.; BRAGA, B. e TUNDISI, J. G. (Orgs.). Águas doces no Brasil: capital ecológico, uso e conservação. São Paulo: Escrituras Editora, 2002.

SILVA, A. de S; HERMES, L. C. Avaliação da qualidade das águas: manual prático. Brasília: EMBRAPA - Informação Tecnológica, 2004. 55p.

SILVEIRA, M. P. Aplicação do biomonitoramento para avaliação da qualidade da água em rios. Embrapa Meio Ambiente. Jaguariúna, 2004. 68p.

TOLEDO, G.L., NICOLELLA, G. Índice de qualidade de água em microbacia sob uso agrícola e urbano. Embrapa Meio Ambiente, Scientia Agricola, v.59, n.1, p.181-186, 2002.

TUCHOBANOGLOUS, G.; SCHROEDER, E. D. Water quality - characteristics, modelling, modfication. AddisonWesley Publ. Co., EUA, 1985. 